\title{
Oscillations of laboratory populations of the polychaete Capitella capitata (Type I): their cause and implications for natural populations
}

\author{
Edward J. Chesney, Jr.* and Kenneth R. Tenore* \\ Skidaway Institute of Oceanography, Post Office Box 13687, Savannah, Georgia 31416, USA
}

\begin{abstract}
Populations of the polychaete Capitella capitata (Type I) were grown in the laboratory under constant conditions of food input, temperature, and salinity. Population biomass and numbers oscillated with a period of approximately 6 to $8 \mathrm{mo}$ and population peaks ranged from 120,000 to 150,000 indiv. $\mathrm{m}^{-2}$. Estimates of carrying capacity of the population along with analyses of the reproductive output show these populations are overshooting their equilibrium density $(\mathrm{K})$ due to high intrinsic growth rate ( $\mathrm{r}$ ) and time lag associated with reproduction. We conclude that populations of opportunistic species, such as C. capitata, colonizing an unexploited environment in nature will also overshoot the carrying capacity of the environment when conditions favor rapid population growth. When combined with normal environmental variability (i. e. temperature, food supply) the tendency to overshoot carrying capacity can result in explosive population growth followed by sharp declines. These growth patterns can result in their eventual replacement by other species. We attempt to reconcile the frequent observation of cyclic population growth in laboratory studies with the lack of examples in field studies. A variety of factors in nature affect population growth pattern, such as environmental variability, species attributes (i.e. fecundity, reproductive cycle, territoriality, ectothermy and endothermy) and species interactions (i. e. rate of predation and the relation between prey and predator growth rates). Changes in population growth caused by these factors can: (1) eliminate the cyclic population growth or (2) distort and obscure the pattern sufficiently so it cannot be recognized by simply observing population patterns over time.
\end{abstract}

\section{INTRODUCTION}

In attempting to unravel spatial and temporal patterns in natural communities, biologists long ago recognized that many natural populations undergo regular long-term fluctuations (Elton, 1924). Irregular patterns of change are classified as oscillations or, if the pattern recurs with regular frequency, are termed cycles (see Finnerty, 1980 for a more detailed definition).

Since the early studies of population growth a wide variety of mathematical analyses - such as Fourier, spectral, and autocorrelation analysis - have been used to delimit cycles of natural populations. In addition, simulations of population dynamics using a variety of population growth models (Caswell, 1972; May,

\footnotetext{
- Present address: Center for Estuarine and Environmental Studies, Chesapeake Biological Laboratory, P.O. Box 38, Solomons, Maryland 20688, USA
}

1973, 1976, 1979; Tanner, 1975; Hassell et al., 1976) established a theoretical basis for cycles, and numerous laboratory studies of single species populations confirmed their existence. Many of the early descriptions of population oscillations were from studies of field populations of small mammals such as lemmings (Shelford, 1943; Pitelka, 1973), lynx (Elton, 1942) and hare (MacLulic, 1937) but examples exist for field populations of insects (Bigger, 1976) and for laboratory populations such as blowflies (Nicholson, 1950), bacteria (Harrison, 1973), cladocerans (Pratt, 1943; Slobodkin, 1954), houseflies (Taylor and Sokal, 1976), mites (Huffaker, 1958), protozoans (Salt, 1967) and rotifers (Halbach, 1978). Studies of single species populations in the laboratory provide much of the knowledge of population oscillations. One problem in the study of cyclic population growth has been to relate the theoretical understanding of cycles to observations of population growth in the field. The number of examples of cyclic population growth in nature are few 
compared to the potential for cycles the theory predicts. This dilemma can be partially understood by recognizing that most of the examples of cyclic population growth in the laboratory are for ectothermic invertebrate species. Cultured under optimal conditions in the laboratory, many invertebrate species with attributes favoring rapid population growth are likely to display cyclic population growth. For these same species in the field a cyclic growth pattern may not be evident. Nevertheless, the pattern of growth realized by these species in the field will be influenced by the same factors causing their cyclic growth in the laboratory and will render a growth pattern uniquely different from those species without the capacity for cyclic growth. Thus, it is important to understand how these patterns may develop, if we want to understand population dynamics in the field.

During studies of the population dynamics of the opportunistic polychaete Capitella capitata (TYpe I of Grassle and Grassle, 1976) regular long-term oscillations in population parameters were recognized and investigated in an attempt to determine their cause. In this paper we describe oscillations observed in laboratory populations of the opportunistic polychaete Capitella capitata (Type I), detailing their causes and discussing which factors can affect the oscillations. We also relate these laboratory results to field situations by discussing from a theoretical perspective the potential for population cycles of $C$. capitata in nature and, finally, we hypothesize why we do not see, or perhaps do not recognize population oscillations as a more widespread phenomenon in nature.

\section{MATERIALS AND METHODS}

Populations of the polychaete Capitella capitata were cultured on a $2 \mathrm{~cm}$ layer of sieved $(<0.3 \mathrm{~mm}$ ) beach sand placed in $0.25 \mathrm{~m}^{2}$ trays. Each tray initially received ca. 400 ind $\mathrm{m}^{-2}$. Each population was fed Gerber's mixed cereal at a rate of $3.5 \mathrm{~g} \mathrm{dw} \mathrm{m}^{-2} \mathrm{~d}^{-1}$ (90 $\left.\mathrm{mg} \mathrm{N} \mathrm{m}^{-2} \mathrm{~d}^{-1}\right)$ ( $\mathrm{dw}=$ dry weight; $w \mathrm{w}=$ wet weight). All cultures were maintained on flowing filtered $(1 \mu \mathrm{m})$, temperature-regulated $\left(20^{\circ} \mathrm{C}\right)$ seawater (24 to $27 \%$ ) for the duration of the experiment.

The populations used to demonstrate the oscillations are pairs of control trays from 2 different experiments on the effects of predation on the population dynamics of Capitella capitata (Chesney and Tenore, in press). These trays were kept in darkness except while sampling or during maintenance of the cultures. Controls were sampled every other week and only 2 samples ( 2 cores sample ${ }^{-1}$ ) were used to estimate the population. These cultures remained essentially as monocultures of $C$. capitata throughout the experiments, although meiofauna (copepod Tisbe holothuriae, nematodes, protozoans) were present in low concentrations (D. Alongi, pers. comm.).

To avoid sampling the same site repeatedly, sample sites were chosen from a randomized sequence of numbers. Distribution of Capitella capitata within the trays was directly affected by the distribution of food supply. Circulation within the trays resulted in an edge effect along the walls. This edge effect caused the food supply and thus $C$. capitata to be distributed at a $30 \%$ lower density along the edge than in the middle of the trays. Therefore the trays were divided into inner and outer sampling zones of approximately equal area $\left(.125 \mathrm{~m}^{2}\right)$. This sampling strategy improved the experimental design by enhancing the accuracy of the population estimates.

In a separate experiment we followed the long-term trends of Capitella capitata larvae settlement to document changes in reproductive output as popuiation biomass and numbers change. A population of $C$. capitata was started in a $2.75 \mathrm{~m}^{2}$ tank and fed at the same food ration as the smaller trays $\left(0.25 \mathrm{~m}^{2}\right)$. Trochophore larvae of $C$. capitata (Type I) are briefly meroplanktonic, settling from the water column within $24 \mathrm{~h}$ (Grassle and Grassle, 1976). This behavior allowed us to estimate larval settlement by a simple assay technique. A thin layer of sieved beach sand was placed in small plastic weighing dishes and suspended on a Plexiglas platform in the water above the culture of $C$. capitata. Prior to the main experiment we tested the effect of the presence or absence of food (Gerber mixed cereal) on the rate of larval settlement. Larvae settled 42 times higher in trays with food than trays without $(\overline{\mathrm{x}}=54.5 \pm 24.4$ [S.D.] [ $\mathrm{N}=6$ ] larvae per dish with food versus $\bar{x}=1.3 \pm 0.9$ larvae per dish $[N=6]$ without food; significant difference in means at $\mathrm{p}<.001)$. Therefore, a layer of food $(15 \mathrm{mg} \mathrm{dw}$ Gerber mixed cereal) was spread evenly across the surface of the sand to serve as a stimulus for larval settlement. After $48 \mathrm{~h}$ the dishes were removed from the tank and the newly settled larvae counted (2 replicate dishes) using a dissecting scope (12-25X). Estimates of larval settlement were made weekly. At the same time population biomass and numbers were estimated biweekly using the same procedure as in the small trays, except that 6 samples were taken (1 core sample ${ }^{-1}$ ).

\section{RESULTS AND DISCUSSION}

Populations of Capitella capitata (Type I) oscillated in numbers and biomass (Fig. 1). The oscillations are demonstrated by control trays from 2 different experiments run at different times under essentially the same conditions (Fig. 1). In the first experiment densities 

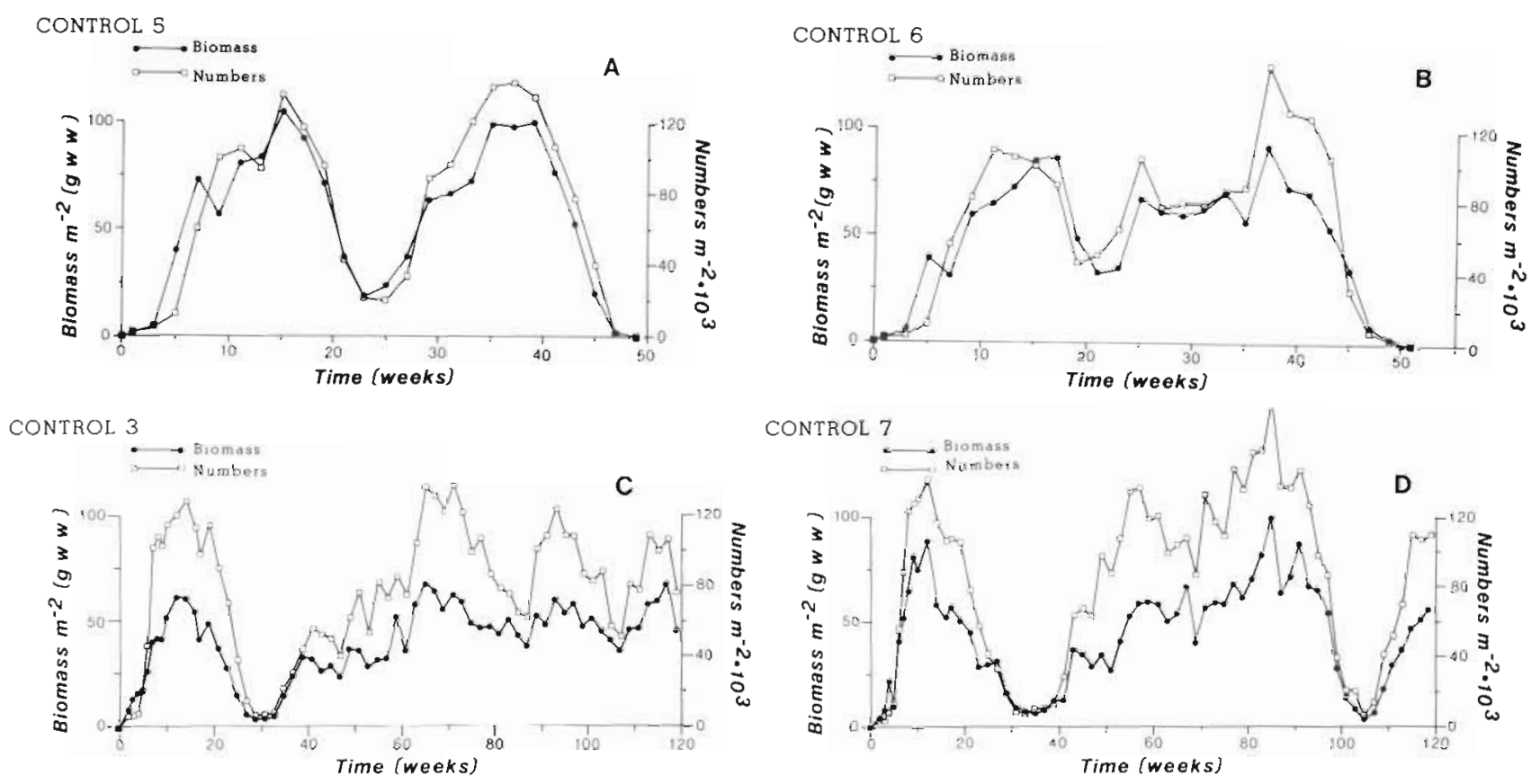

Fig. 1. Capitella capitata (Type I). (A, B) Oscillations in biomass and number of populations for replicate control trays from the first experiment; $(C, D)$ controls for the second experiment

ranged from $<20,000$ indiv. $\mathrm{m}^{-2}$ and $10 \mathrm{~g}$ ww $\mathrm{m}^{-2}$ to $130,000 \mathrm{~m}^{-2}$ and $90 \mathrm{~g} \mathrm{ww} \mathrm{m}^{-2}$ and had a period of approximately $24 \mathrm{wk}$. In the second experiment the amplitude was similar but the periods of the oscillations were longer ca. 30 to $35 \mathrm{wk}$.

Significant differences between replicates and between experiments were tested with regression analysis for periodic data (Bliss, 1970). Replicate controls were not significantly different in the first experiment, but were significantly different in the second experiment. Differences between controls in the first and second pair of controls were also significant. This difference was due to the longer period and duration of the populations in the second experiment. In the first experiment populations died out completely after 2 oscillations. In the subsequent experiments the populations recovered after their second decline.

\section{Potential for oscillations in Capitella capitata}

Studies of population oscillations in the field have categorized potential causal factors as intrinsic to a species (i.e. birth rate, generation time) or as extrinsic factors (weather, daylength, temperature, disease, predation, competition) (Finnerty, 1980). While investigating potential causes of oscillations in Capitella capitata, we considered several extrinsic factors as possible causes for the oscillations. One possibility is that buildup of metabolites cause the crashes in the populations. But this seemed unlikely because $C$. capitata is known to thrive in organically enriched polluted environments. Secondly, in a flow-through seawater system dilution should prevent buildup of soluble metabolites within the culture. To be certain the populations were not declining due to the buildup of waste products, we transferred populations in a declining phase of growth to trays with clean sand. We stocked at their ambient density and at much lower density $\left(200 \mathrm{~m}^{-2}\right)$. The population at ambient density continued to decline while those transferred at a low density reproduced within a few weeks. This supports the idea that metabolic wastes are not the cause for the crashes. Thus, identified extrinsic causes have either been eliminated by controlled experimental conditions or by reason, leading us to consider an intrinsic factor as the cause of the oscillations in C. capitata.

Population ecologists have long considered intrinsic population parameters as important components of population growth patterns. Hutchinson (1948) was one of the first ecologists to suggest oscillations were not unexpected; he pointed out that a simple time lag introduced into the logistic equation would result in population oscillations.

$$
\frac{\mathrm{dN}}{\mathrm{dt}}=\mathrm{rN} \frac{\left(\mathrm{K}-\mathrm{N}_{\mathrm{t}-\mathrm{r}}\right)}{\mathrm{K}}
$$

where $\mathrm{r}=$ rate of population increase $\mathrm{T}=$ time delay. This form of the logistic has been used to develop the theoretical relation between the rate of population increase (r) and the time lag ( $\mathrm{T}$ ) component of a growing population. May (1973) described population 
behavior from models incorporating time lags ranging from damped oscillations at moderate values of $r T$ $(<1 / 2 \pi)$ to stable limit cycles at higher values $(r T>1 / 2 \pi)$. In this model oscillations occur whenever the time delay is longer than the natural response time of the system $(1 / r)$. The biological expression of a time lag is the time it takes a density-dependent factor to influence birth and death processes. For example, May (1973) stated, '. . . time delay in a resource limitation is essentially a natality lag.' Thus, the time it takes for a mature female to generate offspring represents a real lag in any biological system. Similarly, if reproduction takes place at a sufficiently high rate, the time it takes for food limitation to act as a density-independent factor (shutting down reproduction) represents a significant time delay as well. The effect of these delays in the negative feedback mechanism would be especially important for continuously reproducing species because energetic limitation is just as important as seasonality and temperature in determining when reproduction takes place. The consequences of a time delay is that under constant environmental conditions a population will tend to overshoot its carrying capacity resulting in an oscillatory return to equilibrium, or a stable limit cycle.

Determining whether or not the oscillations in our populations are due to 'overshoot' associated with a time delay in density-dependent effects required knowledge of: (1) reproductive pattern with time and, (2) carrying capacity of the population for a given set of environmental conditions. A comparison of long-term population dynamics of Capitella capitata with the rate of larval settlement shows reproductive output is not continuous (Fig. 2). Although the oscillations are not as clearcut as in the small tanks (partially due to greater sampling variability in the large tanks) a distinctive pattern developed. High rates of larval settlement occurred during periods of population increase, followed by a period population decline when settlement of new larvae approached zero. Pratt's (1943) study of the effect of temperature on the long-term population dynamics of the cladoceran Daphnia magna provides one of the few studies with comparable data. He followed births and deaths of oscillating populations at $25^{\circ} \mathrm{C}$ and found high birth rates during population increases, followed by low birth rate, coupled with high death rates during population declines. Pratt stated, Oscillations consist essentially in the successive "overshooting" and "undershooting" of a theoretical equilibrium density.' Thus, he recognized this pattern as one expected from a population overshooting its carrying capacity and subsequently declining due to density-dependent effects on survival. Goulden and Hornig (1980) investigated the mechanism of the time lag involved in the oscillations of D. galeata mendotae

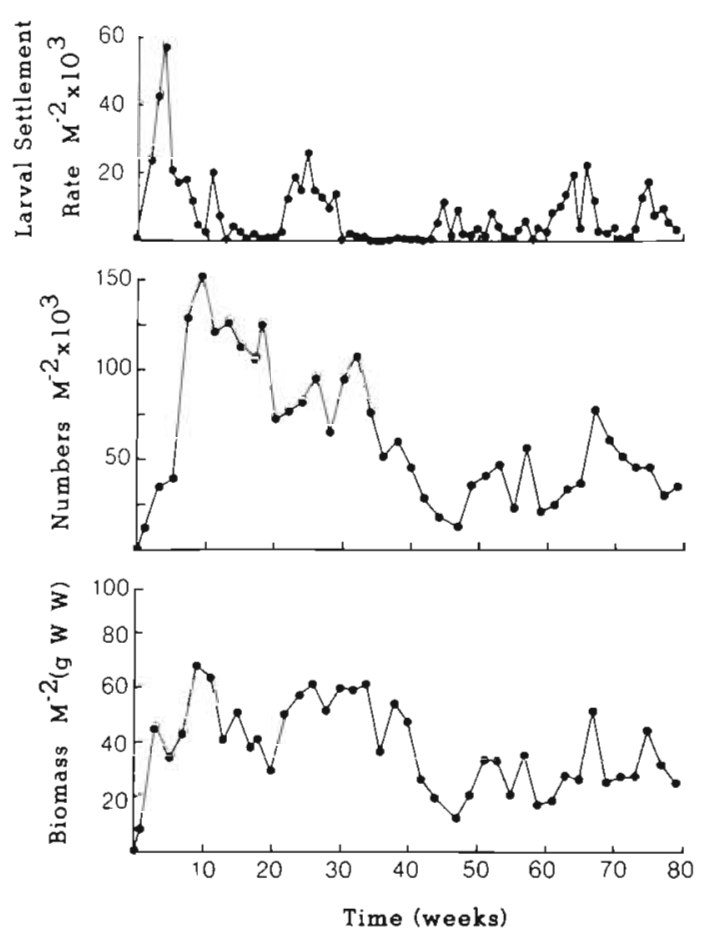

Fig. 2. Capitella capitata (Type I). Rates of larvae settlement compared with population biomass and numbers over time. Note peak in larval settlement during periods when the population is increasing, and the low larvae settlement during periods of population decline

and found it is a function of the energy reserves accumulated by an individual.

Detailed knowledge of the environmental conditions a population encounters is needed to estimate the carrying capacity of a population. For example, temperature strongly influences the metabolic demands and growth rates of invertebrates (Newell and Branch, 1980). Therefore, to determine the carrying capacity of a poikilothermic species such as Capitella capitata, individual growth rates for a known set of environmental conditions (temperature, food ration, population density, size distribution) must be known. Weight specific growth rates were measured for 3 size classes of C. capitata at $20^{\circ} \mathrm{C}$ over a range of densities and biomasses (Tenore and Chesney, in press). Growth rates were plotted against ration/biomass ratio (food ration per unit weight of worm) for each size class. Where the regression crosses the $\mathrm{X}$-axis estimates the carrying capacity for a given size class. A mean carrying capacity for 3 size classes of $C$. capitata was estimated at $56.6 \mathrm{~g} \mathrm{ww}^{-2}\left( \pm 1.8 \mathrm{~S}\right.$. D.) for $20^{\circ} \mathrm{C}$ and a ration of $90 \mathrm{mg} \mathrm{N} \mathrm{m}^{-2} \mathrm{~d}^{-1}$. This represents the maximum mean population biomass supportable if $100 \%$ of the ration were utilized by $C$. capitata. If we compare the estimated mean with those observed in the experimental controls over time, the experimental means were 
somewhat lower, indicating some portion of the food was being utilized by microbial or meiofauna components of the system. Nevertheless, the populations spent a large amount of time above and below the theoretical carrying capacity. Thus, these data support the reproductive data in suggesting the population oscillations in the laboratory resulted from overshoot of carrying capacity.

\section{Potential for oscillations in nature}

If we ask ourselves if all species have the propensity to oscillate, the answer would certainly be ' $\mathrm{No}$ '. Finnerty (1980) in summarizing what we have to explain about population oscillations states, 'A simple population growth equation with time lags can oscillate, but it is unclear why, since this produces cycles quite easily, more cycles do not exist.' Other biologists have expressed similar concerns about the relative paucity of examples of species undergoing regular long-term oscillations in nature. For example, we see single peaks of growth in field populations of Capitella capitata but not the long-term oscillations observed in the laboratory (Grassle and Grassle, 1974; McCall, 1977).

To place our experimental data into perspective we need to rationalize first the pattern of population growth seen in natural population of Capitella capitata. This requires predictions of their population behavior over the range of environmental extremes that can support their population growth. Rate of population increase ( $r$ ) is as important component of the time delay logistic affecting a population's potential for oscillations (recall that increasing ' $r$ ' increases the value of $r T$ ). Furthermore, ' $r$ ' is a function of birth and death processes $(\mathrm{r}=\mathrm{b}-\mathrm{d})$ so any factor affecting birth (b) or death rates (d) will affect population growth.

Temperature is an important variable affecting population growth rate and rates of reproductive development, especially in poikilothermic organisms. Two studies of oscillating populations demonstrate the importance of temperature effects on population oscillations (Pratt, 1943; Halbach, 1978). Both Pratt (working with cladocerans) and Halbach (working with rotifers) found that lower temperatures generated stable populations while higher temperatures resulted in oscillations. May (1979), referring to Halbach's data, suggested that a likely interpretation is that increasing temperature leads to faster biological growth rate, $r$, and thus to increasing values of rT. Mean generation time and hence intrinsic growth rate of Capitella capitata is similarly affected by temperature (Oshida, 1976). Thus, C. capitata population dynamics would be predicted to react similarly to temperature.
Population growth and starvation experiments show Capitella capitata are highly sensitive to food ration. Tenore (1977) grew populations over a wide range of food levels and found a linear increase in biomass with increased food, indicating intraspecific competitive effects are minimal for $C$. capitata even at high densities. Densities of over 200,000 ind $\mathrm{m}^{-2}$ have been reported in field studies (Grassle and Grassle, 1974) and starvation of a growing population in the laboratory occurs within 4 to $8 \mathrm{wk}$ after food supply is stopped (Fig. 3). Thus any population of C. capitata persisting through time requires a continuous supply of food.
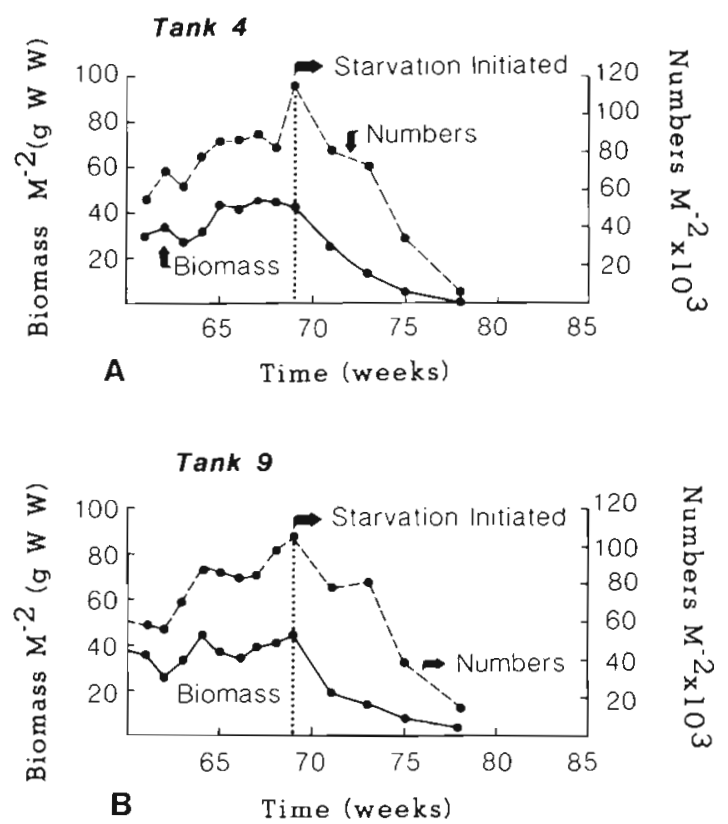

Fig. 3. Capitella capitata (Type I). Population decline after continuous input of food is stopped. Rapid loss of weight, reflected in decreased mean size of individuals, is followed by a decline in numbers. Rate of starvation depends on relative stage of oscillation. The starved population was held in check by predation prior to starvation

If Capitella capitata are not limited by intraspecific effects but by food resource, food and temperature can act in combination to accentuate the oscillatory nature of a population or to distort the pattern sufficiently to make cyclical population behavior undistinguishable. The difficulty is to recognize these patterns in spite of the obscuring effect environmental variability can have on observed population growth patterns.

For example, a typical seasonal pattern of temperature and food input for deposit-feeding benthos in temperate seas consists of detritus settling to the bottom after the winter-spring bloom followed by a rapid rise in water temperature (Graf et al., 1982). Thus, the benthos initially grow under excellent conditions of food and temperature. Summer brings moderate food 
input to the benthos, combined with higher metabolic demands. These shifts in food input and metabolic needs effectively result in a continuously changing equilibrium point for the population. From a general equation for polychaete respiration (Banse et al., 1971), metabolic demands were estimated to be approximately $40 \%$ higher at 14 than at $8{ }^{\circ} \mathrm{C}$. What this means to a polychaete population growing according to the time delay logistic is that, depending on whether the temperature is increasing or decreasing, the equilibrium point for the population will increase or decrease by $40 \%$. The net response of the population will depend upon the population density and the relative stage the population has reached in the oscillation. Thus, a population following the time delay form of the logistic will not only tend to oscillate due to the time delay factor inherent in the biological system, but will experience changing equilibrium points in a variable environment.

This simple model of environmental variability can be illustrated using concepts from simple wave theory. Both population oscillations and waves can be represented by a sine curve of wavelength $2 \pi$. Similarly, environmental variables may be represented as sine curves with a variety of periods, amplitudes and phases. Fig. $4 \mathrm{~A}$ shows the predicted relation between a population oscillating $(\mathrm{r} T>1 / 2 \pi)$ under constant conditions and the same population growing under environmental variability. The nodes and antinodes of the variable waves are represented as positive or negative variable effects on an oscillating population. Thus the node of a variable wave in the model increases birth and growth processes and the antinode decreases birth processes (either by decreasing $b$ or increasing d). The phase of these variable waves can be shifted to look at different combinations of variable effects. Fig. 4 E, F is a representation of the net effect of imposing a variable environment on an oscillating population. The outcome of the model depends upon whether the variable nodes and antinodes are in phase or out of phase with the phase of the population oscillation. Although the model is oversimplified, it does show how a population growing in a variable environment can display a range of population behavior from accentuated boom and bust peaks to relatively stable low level fluctuations and how these patterns might obscure a cyclic pattern intrinsic to the species. Thus, for an opportunistic species, such as Capitella capitata, their inability to persist as dominant components of benthic communities may simply be the result of environmental variability enhancing the rapid population growth and rapid population declines inherent in the life history characteristics of the species.

Traditional views have labelled opportunists as poor competitors primarily because of their inability to per-
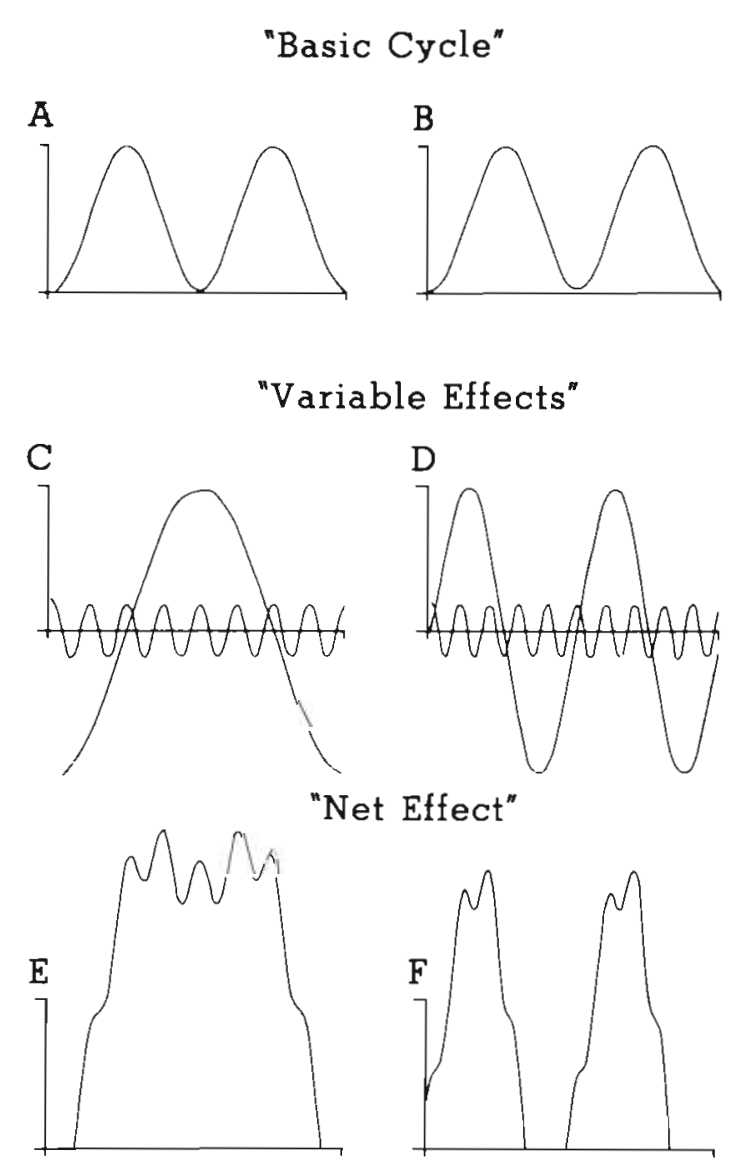

Fig. 4. Capitella capitata (Type I). Potential effect of a variable environment on observed pattern of population growth The different patterns are generated by imposing: sine curves on the main sine curve (A) representing cyclic population growth; positive and negative sine curves $(C, D)$ on the basic cycle, resulting in $(E, F)$. In this simple model the nodes and antinodes of the variable curves (C, D) represent positive and negative effects of some environmental factor on population growth

sist locally as dominant components of a community. This traditional view is based largely on circumstantial evidence. Gray (1981) states that the classical argument would be that Capitella is outcompeted, but no one has shown this. It may just be that the population becomes senile and dies down, leaving space for later colonists that have a more limited breeding cycle with larvae only available over a relatively short period of time: 'Some investigators believe that current ideas of equilibrium niche theory suggests competitive interaction in nonequilibrium populations are likely to be low and that sufficiently far from equilibrium there is no limit to the number of species coexisting, nor to their similarity (Caswell, 1982). Caswell goes on to develop the relation between time spent increasing, time spent decreasing, and time to extinction, using the LotkaVolterra competition equations. He suggests that so- 
called equilibrium species are not necessarily at equilibrium, but simply spend a long time in the 'declining' stages of population growth and that nonequilibrium species (i. e. r-selected), spend a large portion of time in an 'increasing' phase. If most of a species time is spent in an increasing phase, the time required for extinction will be relatively short compared to a species spending most of its time in a declining phase. Thus the competitive ability of $\mathrm{r}$ selected species may not be poor (at least in the traditional sense), but the time it takes for the decline of the population when compared to $\mathrm{k}$-selected species may be short. Thus, displacement by another species would take place not as a result of greater competitive ability on the part of a newer species presence, but due to the instability of a declining population already beyond its carrying capacity and only capable of decline in the presence of another species. This distinction may be subtle when viewing the overall process of species replacements in pioneering communities, but one that should be considered if we want a complete understanding of why species replace one another.

Finally, it is important to recognize that certain biotic characteristics, such as the presence of a self-regulatory mechanism (e.g. territoriality) or interactions in a predator-prey association can stabilize the population dynamics of a species with the biotic potential for cyclic population growth (Tanner, 1975). For example, a predator-prey association can stabilize an unstable species if the predator's intrinsic growth rate is high enough to keep the realized rate of increase of its prey low (Tanner, 1975).

The principal of self-limitation stabilizing a population would apply equally well to both a single species population and a population in predator-prey association. For instance, in the marine environment many polychaetes, such as Nereis virens and $N$. diversicolor (Reise, 1979), are territorial. These species are relatively $\mathrm{k}$-selected species and would be expected to maintain relatively stable populations compared to opportunistic polychaetes. Thus territoriality would promote population homeostasis in the absence of predator control.

Thus, sometimes in nature we see the pattern of population growth predicted by the time delay logistic. But for many species with the biotic potential for cyclic population growth we do not see it because: (1) oscillation never occurs because of an environmental factor limiting growth rate ( $\mathrm{r}$ ) so the effective rate of increase is low, or (2) environmental variability is sufficient to generate a distorted pattern of growth that is not easily recognized as cyclic, or (3) a species growth rate is held in check by its own self-regulatory mechanism (e.g. territoriality) or by its interactions with other species (e.g. predation; predator self-limitation).

\section{SUMMARY}

Capitella capitata (Type I) undergo population oscillations in the laboratory because of successive overshooting and undershooting of population carrying capacity. Many other species are oscillatory; examples exist for field and laboratory populations. These species all have high intrinsic growth rates and probably lack any form of self-limitation (e.g. territoriality) to maintain stability. Environmental variability is an important factor altering the intrinsic population patterns of species, especially in the case of poikilothermic species. Thus any species overshooting a carrying capacity may not behave as predicted by the timedelay logistic due to shifts in equilibria caused by changes in resource abundance or metabolic demands.

Dealing with a community containing both a prey and a predator introduces additional factors affecting stability. Although the likelihood of a stabilizing attribute occurring in a complex community is greater than in a simple community, complexity alone will not result in stability. We must consider the attributes of individual species, the relation between prey and predator attributes such as population growth rates ( $r$ ) and self limitation, and the interaction of climatic condition and a species environmental requirements when predicting stability versus oscillations.

Acknowledgements. We thank H. P. Jeffries, W. H. Krueger, D. W. Menzel and R. G. Wiegert for comments on the manuscript. We also thank the people who helped with the sampling, especially Jim Schneider and Rick Fredholm. This work was supported in part by the Ocean Science Division of the National Science Foundation (Grant No. OCE-82-00385).

\section{LITERATURE CITED}

Banse, K., Nichol, F. H., May, D. R. (1971). Oxygen consumption by the seabed III on the role of macrofauna at three stations. Extrait de Vie et Millieu. Troisième Symposium European de Biologie 22 (Suppl.): 31-52

Bigger, M. (1976). Oscillations of tropical insect populations. Nature, Lond., 259: 207-209

Bliss, C. I. (1970). Statistics in biology: methods for research in the natural sciences, Vol. 2, McGraw-Hill, New York, p. 210-287

Caswell, H. (1972). A simulation study of a time lag population model. J. theoret. Biol. 34: 419-439

Caswell, H. (1982). Life history, theory and the equilibrium status of populations. Am. Nat. 120(3): 317-339

Chesney, E. J., Jr., Tenore, K. R., (in press). Effects of predation and disturbance on the population growth and dynamics of the polychaete Capitella capitata (Type I) Mar. Biol.

Elton, C.S. (1924). Periodic fluctuation in the numbers of animals: their causes and effects. J. exp. Biol. 2: 119-163

Elton, C. S. (1942). The ten-year cycle in numbers of lynx in Canada. J. Anim. Ecol. 11: 215-44

Finnerty, J. P. (1980). The population ecology of cycles in small animals. Yale University Press, Yale 
Graf, G., Bengtsson, W., Diesner, U., Schulz, R., Theede, H. (1982). Benthic response to sedimentation of a spring phytoplankton bloom: process and budget. Mar Biol. 67: 201-208

Grassle, J. F., Grassle, J. P. (1974). Opportunistic life histories and genetic systems in marine benthic polychaetes. $J$. mar. Res. 32(2) : 253-284

Grassle, J. P., Grassle, J. F. (1976). Sibling species in the marine pollution indicator Capitella (polychaeta). Science, N. Y. 192(20): 643-659

Goulden, C. E., Hornig, L. L. (1980). Population oscillations and energy reserves in planktonic clodocera and their consequences to competition. Proc. natn. Acad. Sci. U.S.A. $77(3): 1716-1720$

Gray, J. S. (1981). The ecology of marine sediments. Cambridge University Press, Cambridge

Halbach, U. (1978). Populationdynamik planktischer Rotatorien. Verh. Ges. Oekol. 7: 173-183

Harrison, D. E. F. (1973). Undamped oscillations occurring in continuous cultures of bacteria. In: Chance, B., Pyke, E. K., Ghosh, A. K., Hess, B. (ed.) Biological and biochernical oscillators. Academic Press, New York, p. 399-410

Hassell, M. P., Lawton, J. H., May, R. M. (1976). Patterns of dynamical behavior in single-species populations. $\mathrm{J}$. Anim. Ecol. 45: 471-486.

Huffaker, C. B. (1958). Experimental studies on predation: dispersion factors and predator-prey oscillations. Hilgardia 27 : $343-383$

Hutchinson, G. E. (1948). Circular causal factors in ecology. Ann. N. Y. Acad. Sci. 50: 221-246

MacLulich, P. A. (1937). Fluctuations in the numbers of the varying hare. Univ. Toronto Stud. Biol. Ser. 43

May, R. M. (1973). Stability and complexity in model ecosystems, 2nd ed. Princeton University press, Princeton

May, R. M. (1976). Models for single populations. In: May, R. M. (ed.) Theoretical ecology: principles and applications. Saunders, Philadelphia

May, R. M. (1979). The structure and dynamics of ecological communities. In: Anderson, R. M., Turner, B. D., Taylor, L. R. (ed.) Population dynamics. Blackwell Scientific, Oxford, p. $307-320$

McCall, P. L. (1977). Community patterns and adaptive strategies of the infaunal benthos of Long Island Sound. J. mar. Res. 35(2): 221-266

Newell, R. C., Branch, G. M. (1980). The influence of temperature on the maintenance of metabolic energy balance in marine invertebrates. Adv. mar. Biol. 17: 326-396

Nicholson, A. J. (1950). Population oscillations caused by competition for food. Nature, Lond. 165: 476-477

Oshida, P. S. (1976). The effects of temperature on the survival and reproduction of four polychaete species: Capitella capitata, Neanthes arenaceodentata, Dinophilus sp. and Ctenodrilus serratus. M. S. thesis, California State University, Long Beach

Pitelka, F. A. (1973). Cyclic pattern in lemming populations near Barrow, Alaska. In: Britton, M. E. (ed.) Alaska Arctic Tundra. Arct. Inst. N. Am. Wash. Tech. Pap. 25: 199-215

Pratt, D. M. (1943). Analysis of population development in Daphnia at different temperatures. Biol. Bull. mar. biol. Lab., Woods Hole 85: 116-140

Reise, K. (1979). Spatial configurations generated by motile benthic polychaetes. Helgoländer wiss. Meeresunters. 32: 55-72

Salt, G. W. (1967). Predation in an experimental protozoan population (Woodruffia Paramecium). Ecol. Mínogr. $37(2): 113-144$

Shelford, V. E. (1943). The abundance of the collard lemming (Dicrostonyx groenlandicus [Tr.] var. richardsoni mer) in the Churchhill area 1929 to 1940 . Ecology 24: 472-484

Slobodkin, L. B. (1954). Population dynamics in Daphnia obtusa kurz. Ecol. Monogr. 24: 69-88

Tanner, J. T. (1975). The stability and the intrinsic growth rates of prey and predator population. Ecology 56: 855-867

Taylor, C. E., Sokal, R. R. (1976). Oscillations in housefly population sizes due to time lags. Ecology 57: 1060-1067

Tenore, K. R. (1977). Growth of Capitella capitata cultured on various levels of detritus derived from different sources. Limnol. Oceanogr. 22: 936-941

Tenore, K. R., Chesney, E. J., Jr. (in press). The interaction of rate of food supply and population density upon the bioenergetics of the opportunistic polychaete, Capitella capitata (Type I). Limnol. Oceanogr. 